MR. VILLE MYLLYMÄKI (Orcid ID : 0000-0001-5577-1599)

Article type : Original Article

\title{
Association between periodontal condition and the development of type 2 diabetes mellitus - results from a 15-year follow-up study
}

Myllymäki $V^{1}$, Saxlin $\mathrm{T}^{1,2,3}$, Knuuttila $\mathrm{M}^{4,5}$, Rajala $U^{6}$, Keinänen-Kiukaanniemi $\mathrm{S}^{6,7}$, Anttila $\mathrm{S}^{8}$, Ylöstalo $\mathrm{P}^{3,4,5}$

${ }^{1}$ Institute of Dentistry, University of Eastern Finland, Kuopio, Finland

${ }^{2}$ Department of Oral and Maxillofacial Diseases, Kuopio University Hospital, Kuopio, Finland

${ }^{3}$ Research Unit of Oral Health Sciences, University of Oulu, Oulu, Finland

${ }^{4}$ Medical Research Center Oulu, Oulu University Hospital and University of Oulu, Oulu, Finland

${ }^{5}$ Department of Oral and Maxillofacial Surgery, Oulu University Hospital, Oulu, Finland

${ }^{6}$ Center for Life Course Health Research, University of Oulu, Oulu, Finland

${ }^{7}$ Unit of Primary Health Care, Oulu University Hospital, Oulu, Finland

${ }^{8}$ Teaching Health Centre, City of Oulu, Finland

Running title: Periodontal condition and T2DM

Keywords: type 2 diabetes; oral health, periodontal condition; periodontitis; cohort-study

This article has been accepted for publication and undergone full peer review but has not been through the copyediting, typesetting, pagination and proofreading process, which may lead to differences between this version and the Version of Record. Please cite this article as doi: $10.1111 /$ jcpe. 13005

This article is protected by copyright. All rights reserved. 
Correspondence address: Ville Myllymäki

\author{
Heinjoenkatu 2 as 2 \\ 53550 Lappeenranta
}

Finland

Telephone: +358504952254

E-mail: ville.myllymaki@fimnet.fi

Conflict of Interest and Sources of Funding Statement: The authors declare that there are no conflicts of interest in this study. No external funding, apart from the support of the authors' institution, was available for this study. The present study is a part of the Cohort 1935 Survey, which was conducted in the city of Oulu (Finland) between 1990 and 2008.

\title{
Abstract
}

Aim: To study whether periodontal condition is associated with the development of type 2 diabetes mellitus (T2DM).

Materials and Methods: A population-based follow-up study was conducted among persons born in 1935 and living in the city of Oulu, Finland ( $n=395)$. The baseline examinations were done during 1990-1992, and the follow-up examinations were done during 2007-2008. The data were gathered by questionnaires, laboratory tests and clinical measurements. Poisson regression models were used in the data analyses.

Results: The adjusted rate ratios (RR) with $95 \%$ confidence intervals $(95 \% \mathrm{Cl})$ for the incident T2DM among subjects with 4-5 mm deep periodontal pockets $(n=98)$, among subjects with $6 \mathrm{~mm}$ deep or deeper periodontal pockets $(n=91)$, and among edentulous subjects $(n=118)$ were $1.32(95 \% \mathrm{Cl} 0.69$ 2.53), 1.56 (95\% Cl 0.84-2.92) and 1.00 (95\% Cl 0.53-1.89), respectively, compared to dentate subjects without deepened ( $4 \mathrm{~mm}$ deep or deeper) periodontal pockets ( $\mathrm{n}=88)$. The adjusted RR per site (the number of sites with deepened periodontal pockets as a continuous variable) was 1.02 (95\% Cl 1.00-1.04).

This article is protected by copyright. All rights reserved. 
Conclusions: Poor periodontal condition may be a predictor of the development of T2DM. However, the causality between periodontal condition and the development of T2DM remains uncertain.

\section{Clinical Relevance}

Scientific rationale for the study: It has been suggested that infectious periodontal disease affects the development of type 2 diabetes mellitus. However, evidence for this association from largerscale longitudinal studies is limited.

Principal findings: The findings of this longitudinal study suggest that periodontal condition appears to predict the development of type 2 diabetes in an exposure-response manner.

Practical implications: Poor periodontal condition may be an indicator of the future development of type 2 diabetes mellitus.

\section{Introduction}

Type 2 diabetes mellitus (T2DM) is a disease which includes various disturbances in insulin signaling and metabolism, which result in insulin resistance combined with an elevated level of glucose in the blood. When the blood glucose level reaches a certain threshold, the state is classified as diabetes (American Diabetes Association, 2009). The risk factors for T2DM include a number of determinants such as family history of T2DM, overweight or obesity, dietary factors, physical inactivity, a sedentary lifestyle, smoking, abnormal lipids (elevated triglycerides and/or low HDL cholesterol levels), hypertension and inflammation (Chen et al. 2011).

Periodontitis has also been suggested to be associated with the development of T2DM. However, there are only a limited number of longitudinal studies focusing on the relation of periodontitis to the development of T2DM (Borgnakke et al. 2013, Graziani et al. 2018). A recent cohort-study by Winning et al. (2017) reported a consistent association between moderate/severe periodontitis and incident T2DM, suggesting periodontitis as a risk predictor for T2DM. Demmer et al. (2008) also reported a nonlinear association between baseline periodontal disease and incident T2DM, suggesting periodontal disease to be a clinically relevant predictor for T2DM. Ide et al. (2011), on the other hand, found no statistically significant association between periodontal disease and incident T2DM, except among females. Other studies have suggested that periodontitis or poor periodontal 
condition is also associated with other markers of impaired glucose metabolism, such as the development of glucose intolerance (Saito et al. 2004) and the elevation of $\mathrm{HbA}_{1 \mathrm{c}}$ levels (Demmer et al. 2010, Morita et al. 2012). Moreover, the effect of infectious periodontal disease on the therapeutic equilibrium of diabetic patients is supported by a number of studies, which have shown periodontal treatment to have a beneficial effect on the glycaemic control (Engebretson \& Kocher 2013, Janket et al. 2005).

Possible mechanisms linking periodontitis with the development of T2DM may comprise low-level systemic inflammation associated with periodontitis. This includes elevated systemic levels of proinflammatory cytokines, especially interleukin-1 (IL-1), interleukin-6 (IL-6) and tumour necrosis factor- $\alpha$ (TNF- $\alpha$ ) (Taylor et al. 2013) or systemic oxidative stress (Allen et al. 2009). Both pathways lead to insulin resistance and eventually to the development of T2DM (Esser et al. 2014).

Since the role of infectious periodontal disease in the development of T2DM is somewhat obscure, the aim of this study was to investigate whether the severity of periodontal condition as measured by probing pocket depths or edentulousness are associated with the development of T2DM over a 15-year follow-up period.

\section{Material and methods}

The study population consisted of subjects who were all inhabitants of the city of Oulu, Finland, on $1^{\text {st }}$ of October 1990, and were born in 1935. The examinations were conducted in two phases; the baseline examinations between 1990 and 1992 and the follow-up examinations in 2007-2008. At the baseline, 1,008 participants were invited to clinical examinations, of which 780 (77\%) participated and were examined. During the baseline examinations, subjects were screened for diabetes using fasting blood glucose values and a standard two-hour (75-gram) oral glucose tolerance test (OGTT). Fasting blood glucose value determination was based on venous whole blood samples, and the twohour post-load glucose values were based on capillary samples, using hexokinase-glucose-6phosphate dehydrogenase method (Rajala et al. 1995). Diabetes was defined using the criteria set by the World Health Organization (WHO) study group in 1985 (Rajala et al. 1995, WHO 1985); fasting blood glucose $6.7 \mathrm{mmol} / \mathrm{I}$ or more in repeated measurements or OGTT blood glucose $11.1 \mathrm{mmol} / \mathrm{l}$ or more. Based on these measurements, in addition to known history of diabetes, subjects having

This article is protected by copyright. All rights reserved. 
diabetes at baseline were excluded from the present study $(n=59)$. Of the non-diabetic subjects at baseline, 414 participated in the follow-up examinations in 2007-2008. Of those, 19 subjects were excluded from the analyses due to incomplete data about diabetic status. The final study population for this study therefore amounted to 395 participants. The formation of the study population is presented in Figure 1. Besides clinical examinations and laboratory tests, data for this study were collected using questionnaires and interviews. Approval for the study was received from the Ethics Committee of the Faculty of Medicine, University of Oulu, Oulu, Finland.

\section{Figure 1}

\section{Outcome variable}

The outcome variable of this study was type 2 diabetes mellitus (T2DM) diagnosed during the followup period or in the follow-up examinations in 2007-2008. In the follow-up examinations, the diabetes diagnosis was based on the recommendations made by WHO and the International Diabetes Federation (2006); fasting venous plasma glucose $\geq 7.0 \mathrm{mmol} / \mathrm{l}$ and/or two-hour venous plasma glucose $\geq 11.1 \mathrm{mmol} / \mathrm{l}$ after ingestion of 75 grams of an oral glucose load. Venous plasma samples were used, which were drawn in containers with glycolytic inhibitors and centrifuged immediately to separate plasma. Glucose concentrations were determined using hexokinaseglucose-6-phosphate dehydrogenase method (Cederberg et al. 2010).

\section{Explanatory variable}

The explanatory variable of this study was periodontal condition measured as the presence of deepened ( $4 \mathrm{~mm}$ deep or deeper) periodontal pockets. Clinical oral examinations were conducted in the baseline examinations between 1990 and 1991. Periodontal pocket depths were measured from the mesial, buccal, distal and lingual/palatal sites of all teeth, and probing depths $4 \mathrm{~mm}$ or more were registered. The two dentists performing the measurements were given instructions in the same way and their probing techniques were calibrated. The intra-examiner agreement in the diagnosis of periodontal pockets was $96.7 \%$ and the kappa statistic 0.80 for examiner 1 , and $95.3 \%$ and 0.78 for examiner 2 (Sakki et al. 1995). In this study the explanatory variable was categorised as follows: periodontally healthy subjects (dentate subjects with no deepened [ $4 \mathrm{~mm}$ deep or deeper] periodontal pockets), subjects with periodontal pockets with a probing depth of 4-5 mm, subjects with periodontal pockets with probing depth of $6 \mathrm{~mm}$ or more, and edentulous subjects. The 
number of sites with deepened pockets was also used as a continuous variable in analyses among the subpopulation of dentate subjects.

\section{Confounding variables}

The assessment of the hereditary risk of diabetes mellitus was based on the occurrence of diabetes mellitus in the immediate family, and the information was gathered from an interview during the follow-up examinations. The occurrence of diabetes mellitus in the family was surveyed using the following question: "Has anyone in your immediate family or any relatives been diagnosed with diabetes mellitus?" The answer options were the following: "No", which was categorised as low risk; "Yes, diabetes mellitus was diagnosed among grandparents, siblings of parents or cousins (but not among own parents, siblings or children)", which was categorised as moderate risk; and "Yes, diabetes mellitus was diagnosed among parents, siblings or own children", which was categorised as increased risk.

The assessment of physical activity was based on a questionnaire at baseline. Physical activity was categorised into two categories: low physical activity and high physical activity. Physical activity was deemed low if the subject walked or cycled less than 15 minutes on the way to work and exercised only once per week or less during leisure time. Otherwise physical activity was categorised as high.

Dietary habits were categorised into three categories: healthy diet, moderately healthy diet and unhealthy diet. Dietary habits were assessed with the help of three questions in a questionnaire at baseline. The first question was: "How often do you eat fruits, vegetables or root crops?", with the answer options being "daily" vs. "1-2 times a week" vs. "less than once a week". The second question posed was: "What is the fat content of the butter or margarine you use on bread?", and the answer options were "no fat" vs. "low fat margarine" vs. "butter". The third question was: "What do you drink with your meals?", where the answer options for this question were "fat-free (for instance water, fat-free milk or sour milk)" vs. "low fat (light milk or sour milk)" vs. "fat content (fatty milk)". Dietary habits were deemed healthy if the subject selected the healthiest option to all three questions, moderately healthy if the subject selected one unhealthy option, and unhealthy if the subject selected more than one unhealthy option.

This article is protected by copyright. All rights reserved. 
Smoking habits were studied using three questions in a questionnaire answered during the follow-up examinations. The first question was: "Have you ever smoked cigarettes regularly (= almost every day and for at least one year) in your lifetime?", with the answer options being "yes" vs. "no". The second question was: "Do you smoke now (cigarettes, cigars or a pipe)?", where the answer options for this question were "regularly" vs. "occasionally" vs. "no". The third question was: "If you have stopped smoking, at what age did you stop?" Based on these questions, the subject was classified as a non-smoker if the answer for the first question was "no", and a current smoker if the answer for the second question was "regularly". The subject was categorised as a former smoker if the third question was answered.

Clinical examinations included measurement of height and weight and the information was used to calculate each subject's body mass index (BMI) (Cederberg et al. 2010, Rajala et al. 1995). BMI in the follow-up examinations (categorised into three categories: less than 25.0, 25.0-29.9 and 30.0 or more) and absolute change in BMI during the follow-up period (continuous variable) were used as covariates in the multivariate models.

Impaired glucose tolerance (IGT) at baseline was examined according to a standard two-hour (75 grams) OGTT as mentioned earlier. The subject was classified as having IGT according to the WHO criteria, i.e. if the two-hour post-load glucose concentration was between $7.8 \mathrm{mmol} / \mathrm{l}$ and 11.0 mmol/l (Rajala et al. 1995, WHO 1985).

Serum triglyceride and high-density lipoprotein cholesterol (HDL-C) concentrations were analysed in the follow-up examinations. Subjects were categorised to have hypertriglyceridemia if their triglyceride level was over $2.0 \mathrm{mmol} / \mathrm{I}$ (Hegele et al. 2014). HDL-C concentration was deemed low if the HDL-C level was lower than $1.0 \mathrm{mmol} / \mathrm{I}$ (Zimmet et al. 2001). Information about arterial hypertension, diagnosed by a physician, was gathered from a questionnaire in the follow-up examinations.

This article is protected by copyright. All rights reserved. 


\section{Statistical methods}

Rate ratios (RR) with $95 \%$ confidence intervals $(95 \% \mathrm{Cl})$ were estimated using the modified Poisson regression model with a robust error variance (Zou 2004). Statistical analyses were made with the SPSS Statistics release 24.0.0.0 (IBM Corporation, Armonk, New York, U.S.A.) statistical software. Analyses were performed among the total study population and among a subpopulation of those who had never smoked. Analyses using the number of sites with deepened (4 $\mathrm{mm}$ deep or deeper) pockets as continuous variable were also performed among the dentate subjects. The selection of confounding variables was based on knowledge about risk factors and determinants for T2DM. Missing data on any of the categorical explanatory variables was handled by creating an extra category ("missing value") for those variables with missing observations.

\section{Results}

\section{Characteristics of the study population}

The characteristics of the study population according to the periodontal status at baseline and according to the diabetic status in the follow-up examinations are shown in Tables 1 and 2 , respectively. The number of sites with deepened ( $4 \mathrm{~mm}$ deep or deeper) periodontal pockets according to the categories of periodontal condition are presented in Table 3 and Figure 2.

The mean number of sites with a probing depth of $4 \mathrm{~mm}$ or more among subjects with 4-5 mm deep periodontal pockets was 3.9 (standard deviation [SD] 3.6) and among subjects with $6 \mathrm{~mm}$ deep or deeper periodontal pockets 11.6 (SD 8.6). A total of 81 (20.5\%) out of 395 participants examined developed type 2 diabetes mellitus (T2DM) over the approximately 15-year follow-up period. Moreover, the incidence of T2DM in the categories of periodontal condition was $15 \%$ among periodontally healthy subjects (dentate subjects with no deepened periodontal pockets), $21 \%$ among subjects with 4-5 $\mathrm{mm}$ deep periodontal pockets, $27 \%$ among subjects with $6 \mathrm{~mm}$ deep or deeper periodontal pockets, and $19 \%$ among edentulous subjects.

This article is protected by copyright. All rights reserved. 


\section{Results of the multivariate models}

In the multivariate models adjusted for gender, diabetes risk, dietary habits, physical activity, smoking status, BMI, absolute change in BMI during the follow-up period, IGT at baseline, hypertriglyceridemia, low HDL cholesterol and arterial hypertension, subjects with deepened periodontal pockets were found to be at higher risk of developing T2DM compared to periodontally healthy subjects in an exposure-response manner (Table 4). The adjusted rate ratios (RR) with 95\% confidence intervals $(95 \% \mathrm{Cl})$ for the incidence of T2DM among subjects with $4-5 \mathrm{~mm}$ deep periodontal pockets, among subjects with $6 \mathrm{~mm}$ deep or deeper periodontal pockets, and among edentulous subjects were 1.32 (95\% Cl 0.69-2.53), 1.56 (95\% Cl 0.84-2.92) and 1.00 (95\% Cl 0.531.89), respectively, compared to periodontally healthy subjects. A similar association, although stronger, was found in the complementary analyses among subjects who had never smoked. Edentulous subjects were the only exception, among whom an inverse association between periodontal condition and the development of T2DM was observed (Table 5).

Statistically significant association between periodontal condition (the number of sites with deepened [4 $\mathrm{mm}$ deep or deeper] periodontal pockets as a continuous variable) and incident T2DM was found among dentate subjects. The adjusted RR per site with deepened periodontal pocket was 1.02 (95\% Cl 1.00-1.04) (Table 4). Association of similar fashion was found among never-smokers, albeit statistically non-significant (Table 5).

\section{Discussion}

\section{Principal findings}

We observed an exposure-response association, although statistically non-significant, between poor periodontal condition (as measured by the presence of periodontal pocketing that was $4 \mathrm{~mm}$ or deeper) and the development of type 2 diabetes mellitus (T2DM). This was found among the total study population and among those who had never smoked, being stronger among the latter. These findings are in line with non-experimental studies, which have shown that subjects who have periodontitis are more likely to develop T2DM (Awuti et al. 2012, Demmer et al. 2008, Ide et al. 2011, Saito et al. 2004, Winning et al. 2017) compared to periodontally healthy subjects. However, it has to be mentioned, that direct comparison between these studies is somewhat difficult due to differences, for instance, in the definition of the exposure variable.

This article is protected by copyright. All rights reserved. 


\section{Possible mechanisms}

Several plausible explanations for the association of poor periodontal condition with the development of T2DM have been presented. A systemic response against periodontal pathogens causes an elevation in the levels of pro-inflammatory cytokines, especially IL-1, IL-6 and TNF- $\alpha$ (Taylor et al. 2013). These cytokines are considered to have a specific role in the pathogenesis of T2DM (Preshaw et al. 2007, Zhang et al. 2008). It has been postulated that cytokines themselves have adverse effects on cellular signalling critical to glucose metabolism (Colombo et al. 2012, Shirakashi et al. 2013, Southerland et al. 2006), or that cytokines produce a rise in oxidative stress, which leads to cellular damage (Allen et al. 2009, Bullon et al. 2009).

Besides pro-inflammatory cytokines, the persistence of elevated glucose levels may also facilitate a rise in oxidative stress through the development of mitochondrial reactive oxygen species. In addition to direct cellular damage, oxidative stress activates pathways, which in turn increase the production of cytokines (for example TNF- $\alpha$ and IL-1 $\beta$ ). These cytokines might be capable of causing insulin resistance and $\beta$-cell dysfunction (Allen et al. 2009, Evans et al. 2003, Stumvoll et al. 2005), as mentioned earlier.

The role of poor periodontal condition as a factor that predisposes people to T2DM is also supported by findings that show the beneficial effects of periodontal treatment on the clinical markers of diabetes mellitus. The beneficial effect of periodontal treatment on glycaemic control $\left(\mathrm{HbA}_{1 c}\right)$ has been found in a number of studies (Madianos \& Koromantzos 2018, Simpson et al. 2015). In addition, in an intervention study by Sun and co-workers (2011), it was shown that periodontal treatment reduced systemic inflammation, reduced $\mathrm{HbA}_{1 \mathrm{c}}$ levels, reduced insulin resistance and improved $\beta$-cell function.

An alternative explanation is that systemic inflammation related to poor periodontal condition does not have any essential effect on the development of T2DM, and that the observed, mainly statistically non-significant association between periodontal condition and T2DM is spurious due to confounding related to behavioural factors or shared biological factors. In this study, the confounding effect of behavioural factors was controlled for by using a number of behavioural factors as covariates in the multivariate models. In addition, we made complementary analyses

This article is protected by copyright. All rights reserved. 
among participants who had never smoked. This group can be considered homogenous in relation to a number of lifestyle factors, thereby further reducing the confounding effect. As a whole, the study population was homogenous in terms of ethnic origin, gender, change in BMI, smoking status and, self-evidently, age. All these facts reduce the likelihood of confounding as an explanation.

In this context, it should be emphasized that information about immunobiological factors and/or gene polymorphisms, related to shared susceptibility, is insufficient. It is very possible that poor periodontal condition and T2DM have susceptibility factors in common. However, it should also be acknowledged that existing common shared risk factors for these disease entities and the suggested explanatory biological mechanism are not mutually exclusive.

An interesting finding in this study was that the association of edentulousness with T2DM was weaker than that of poor periodontal condition. In fact, in the complementary analyses, we observed that edentulous subjects were less likely to develop T2DM compared to periodontally healthy subjects. The observation - low risk to develop T2DM among edentulous persons - is interesting because edentulous participants had on average more risk factors for T2DM compared with periodontally healthy dentate participants, such as an unhealthy diet, current or past smoking, obesity (BMI 30.0 or more), weight gain (BMI change $\geq 4$ ), hypertriglyceridemia and low HDL-C levels (Table 1). One possible explanation is that most edentulous participants in this cohort have lost their teeth at a young age primarily due to caries in combination with extraction-oriented treatment modalities in the past, and not due to periodontal disease. Thus edentulous subjects could have been at lower risk for developing T2DM, since periodontal disease was treated or alternatively totally prevented by the extraction of teeth. Curvilinear association of tooth loss with systemic disease risk has been reported in several studies (Desvarieux et al. 2003, Tu et al. 2007). The extraction-oriented treatment modalities together with differences in the patterns of seeking treatment could explain the difference in the proportions of edentulousness between women and men.

This article is protected by copyright. All rights reserved. 


\section{Methodological considerations}

Naturally, every non-experimental study is subject to biases. One possible source of bias in this study was the fairly large number of drop-outs during the 15-year follow-up period. Of the 721 nondiabetic subjects participating in the baseline examinations in 1990-1992, complete data about diabetic status in the follow-up examinations in 2007-2008 was available for 395 participants, meaning that more than one third of the original study population was lost for various reasons (Figure 1). The essential question is whether this loss causes bias. Bias can result if the nonparticipation is distributed unevenly in the classes of the outcome variable. It can be assumed that attrition is largest in the lowest socio-economic classes or among those who are severely ill. However, the effect of bias, if such exists, most likely leads to the underestimation of the strength of the association, since it can be expected that non-participation is at least partly related to the outcome, occurrence of T2DM, and mortality.

Another possible source of bias is confounding. It can be related to several factors, including behavioural or biological factors, as mentioned earlier. Although we controlled for the effect of these factors by using multivariate models, it is still possible that residual confounding exists. This residual confounding can be related to unknown factors or due to inadequate application of measurement. It must be acknowledged, for example, that the variables used to measure dietary habits and physical activity in this study were fairly robust.

Analyses for blood glucose levels were performed according to the current recommendations (WHO 1985, WHO \& IDF 2006). Venous whole blood and capillary samples were used at baseline, whereas venous plasma samples were used in the follow-up examinations. This may have had some effect on the results (WHO \& IDF 2006), but these effects should be minimal, since the values were applied for classification purposes only, and not, for instance, for measuring an absolute change in blood glucose levels.

Regarding the explanatory variable, it not only reflects the severity, but also the extent of periodontal pocketing (Figure 2, Table 3). This supports the interpretation that the presence of deepened (4 $\mathrm{mm}$ deep or deeper) periodontal pockets is associated with the occurrence of T2DM in an exposure-response manner. However, statistical significance was not reached, possibly due to the

This article is protected by copyright. All rights reserved. 
low number of subjects and concomitantly reduced statistical power. It is worth noting that it is possible that the inflammatory condition of subjects had changed during the follow-up period, since we have no information about whether participants received any periodontal treatment. It is possible that the inflammatory condition of the participants may have improved due to periodontal treatment, including extractions, or worsened due to progressed periodontal disease. Unfortunately, we have no data on the subjects' periodontal condition throughout the whole 15 years of follow-up. We have some information about the subpopulation of the present study from the early years when their periodontal status was recorded five years after the baseline examination (Ylöstalo et al. 2010). In this study, the periodontal status of the subpopulation remained on average the same between the baseline and the follow-up measurements; the correlation was 0.77 both in periodontal pockets with pocket depth of 4-5 $\mathrm{mm}$ and in periodontal pockets $6 \mathrm{~mm}$ deep or deeper. Another limitation of the explanatory variable in this study admittedly is the lack of clinical attachment loss measurements. However, pocket depth is a good indicator of the present inflammatory condition of periodontium and widely used method in research and in clinical work to assess periodontal health. One limitation is also the lack of information about the reason and timing for tooth loss.

\section{Concluding remarks}

Based on the results of this study, an exposure-response relation exists between the presence of deepened ( $4 \mathrm{~mm}$ deep or deeper) periodontal pockets and the development of type 2 diabetes mellitus (T2DM). Both the exposure-response relation between the poor periodontal condition and T2DM occurrence and the findings of the complementary analyses among never-smokers lend support to the plausibility of these findings. These results are in line with the results of a few earlier studies, although no direct comparisons with other similar studies can be made.

Factors related to the development of diabetes mellitus are manifold and closely related to lifestyle. This makes inferences about causality challenging. Although statistical significance was not reached in all of the analyses in this study, it provides further evidence of a link between periodontal condition and the occurrence of diabetes and suggests that poor periodontal condition might predict the development of T2DM. However, ultimate proof of a causal relation is still lacking.

This article is protected by copyright. All rights reserved. 


\section{References}

Allen E. M., Matthews J. B., O'Connor R., O'Halloran D. \& Chapple I. L. (2009) Periodontitis and type 2 diabetes: is oxidative stress the mechanistic link? Scottish Medical Journal 54, 41-47.

American Diabetes Association. (2009) Diagnosis and classification of diabetes mellitus. Diabetes care 32 Suppl 1, S62-67.

Awuti G., Younusi K., Li L., Upur H. \& Ren J. (2012) Epidemiological survey on the prevalence of periodontitis and diabetes mellitus in Uyghur adults from rural Hotan area in Xinjiang. Experimental Diabetes Research 2012, 758921.

Borgnakke W. S., Ylöstalo P. V., Taylor G. W. \& Genco R. J. (2013) Effect of periodontal disease on diabetes: systematic review of epidemiologic observational evidence. Journal of Clinical Periodontology 40, S135-S152.

Bullon P., Morillo J. M., Ramirez-Tortosa M. C., Quiles J. L., Newman H. N. \& Battino M. (2009) Metabolic syndrome and periodontitis: is oxidative stress a common link? Journal of Dental Research 88, 503-518.

Cederberg H., Saukkonen T., Laakso M., Jokelainen J., Härkonen P., Timonen M., KeinänenKiukaanniemi S. \& Rajala U. (2010) Postchallenge glucose, A1C, and fasting glucose as predictors of type 2 diabetes and cardiovascular disease: a 10-year prospective cohort study. Diabetes Care 33, 2077-2083.

Chen L., Magliano D. J. \& Zimmet P. Z. (2011) The worldwide epidemiology of type 2 diabetes mellitus-present and future perspectives Nature reviews. Endocrinology 8, 228-236.

Colombo N. H., Shirakashi D. J., Chiba F. Y., Coutinho M. S., Ervolino E., Garbin C. A., Machado U. F. \& Sumida D. H. (2012) Periodontal disease decreases insulin sensitivity and insulin signaling. Journal of Periodontology 83, 864-870.

Demmer R. T., Desvarieux M., Holtfreter B., Jacobs D. R.,Jr, Wallaschofski H., Nauck M., Volzke H. \& Kocher T. (2010) Periodontal status and A1C change: longitudinal results from the study of health in Pomerania (SHIP). Diabetes Care 33, 1037-1043.

This article is protected by copyright. All rights reserved. 
Demmer R. T., Jacobs D. R., Jr \& Desvarieux M. (2008) Periodontal disease and incident type 2 diabetes: results from the First National Health and Nutrition Examination Survey and its epidemiologic follow-up study. Diabetes Care 31, 1373-1379.

Desvarieux M., Demmer R. T., Rundek T., Boden-Albala B., Jacobs D. R.,Jr, Papapanou P. N., Sacco R. L. \& Oral Infections and Vascular Disease Epidemiology Study (INVEST). (2003) Relationship between periodontal disease, tooth loss, and carotid artery plaque: the Oral Infections and Vascular Disease Epidemiology Study (INVEST). Stroke 34, 2120-2125.

Engebretson S. \& Kocher T. (2013) Evidence that periodontal treatment improves diabetes outcomes: a systematic review and meta-analysis. Journal of Clinical Periodontology 40 (Suppl.), 153-159.

Esser N., Legrand-Poels S., Piette J., Scheen A. J. \& Paquot N. (2014) Inflammation as a link between obesity, metabolic syndrome and type 2 diabetes. Diabetes Research And Clinical Practice 105, $141-150$

Evans J. L., Goldfine I. D., Maddux B. A. \& Grodsky G. M. (2003) Are oxidative stress-activated signaling pathways mediators of insulin resistance and beta-cell dysfunction? Diabetes $\mathbf{5 2}, \mathbf{1 - 8 .}$

Graziani F., Gennai S., Solini A. \& Petrini M. (2018) A systematic review and meta-analysis of epidemiologic observational evidence on the effect of periodontitis on diabetes. An update of the EFP-AAP review. Journal of Clinical Periodontology 45, 167-187.

Hegele R. A., Ginsberg H. N., Chapman M. J., Nordestgaard B. G., Kuivenhoven J. A., Averna M., Boren J., Bruckert E., Catapano A. L., Descamps O. S., Hovingh G. K., Humphries S. E., Kovanen P. T., Masana L., Pajukanta P., Parhofer K. G., Raal F. J., Ray K. K., Santos R. D., Stalenhoef A. F., Stroes E., Taskinen M. R., Tybjaerg-Hansen A., Watts G. F., Wiklund O. \& European Atherosclerosis Society Consensus Panel. (2014) The polygenic nature of hypertriglyceridaemia: implications for definition, diagnosis, and management. The Lancet Diabetes \& Endocrinology 2, 655-666.

Ide R., Hoshuyama T., Wilson D., Takahashi K. \& Higashi T. (2011) Periodontal disease and incident diabetes: a seven-year study. Journal of Dental Research 90, 41-46.

This article is protected by copyright. All rights reserved. 
Janket S. J., Wightman A., Baird A. E., Van Dyke T. E. \& Jones J. A. (2005) Does periodontal treatment improve glycemic control in diabetic patients? A meta-analysis of intervention studies. Journal of Dental Research 84, 1154-1159.

Madianos P. N. \& Koromantzos P. A. (2018) An update of the evidence on the potential impact of periodontal therapy on diabetes outcomes. Journal of Clinical Periodontology 45, 188-195.

Morita I., Inagaki K., Nakamura F., Noguchi T., Matsubara T., Yoshii S., Nakagaki H., Mizuno K., Sheiham A. \& Sabbah W. (2012) Relationship between periodontal status and levels of glycated hemoglobin. Journal of Dental Research 91, 161-166.

Preshaw P. M., Foster N. \& Taylor J. J. (2007) Cross-susceptibility between periodontal disease and type 2 diabetes mellitus: an immunobiological perspective. Periodontology $200045,138-157$.

Rajala U., Keinänen-Kiukaanniemi S., Uusimäki A., Reijula K. \& Kivelä S. L. (1995) Prevalence of diabetes mellitus and impaired glucose tolerance in a middle-aged Finnish population. Scandinavian Journal of Primary Health Care 13, 222-228.

Report of a WHO Study Group (1985) Diabetes mellitus. Technical report series 727, Geneva: WHO.

Saito T., Shimazaki Y., Kiyohara Y., Kato I., Kubo M., lida M. \& Koga T. (2004) The severity of periodontal disease is associated with the development of glucose intolerance in non-diabetics: the Hisayama study. Journal of Dental Research 83, 485-490.

Sakki T. K., Knuuttila M. L., Vimpari S. S. \& Hartikainen M. S. (1995) Association of lifestyle with periodontal health. Community Dentistry And Oral Epidemiology 23, 155-158.

Shirakashi D. J., Leal R. P., Colombo N. H., Chiba F. Y., Garbin C. A., Jardim E. G., Jr, Antoniali C. \& Sumida D. H. (2013) Maternal periodontal disease in rats decreases insulin sensitivity and insulin signaling in adult offspring. Journal of Periodontology 84, 407-414.

This article is protected by copyright. All rights reserved. 
Simpson T. C., Weldon J. C., Worthington H. V., Needleman I., Wild S. H., Moles D. R., Stevenson B., Furness S. \& Iheozor-Ejiofor Z. (2015) Treatment of periodontal disease for glycaemic control in people with diabetes mellitus. The Cochrane Database of Systematic Reviews 11, CD004714.

Southerland J. H., Taylor G. W., Moss K., Beck J. D. \& Offenbacher S. (2006) Commonality in chronic inflammatory diseases: periodontitis, diabetes, and coronary artery disease. Periodontology 200040 , 130-143.

Stumvoll M., Goldstein B. J. \& van Haeften T. W. (2005) Type 2 diabetes: principles of pathogenesis and therapy. Lancet (London, England) 365, 1333-1346.

Sun W. L., Chen L. L., Zhang S. Z., Wu Y. M., Ren Y. Z. \& Qin G. M. (2011) Inflammatory cytokines, adiponectin, insulin resistance and metabolic control after periodontal intervention in patients with type 2 diabetes and chronic periodontitis. Internal Medicine (Tokyo, Japan) 50, 1569-1574.

Taylor J. J., Preshaw P. M. \& Lalla E. (2013) A review of the evidence for pathogenic mechanisms that may link periodontitis and diabetes. Journal of Periodontology 84, S113-S134.

Tu Y. K., Galobardes B., Smith G. D., McCarron P., Jeffreys M. \& Gilthorpe M. S. (2007) Associations between tooth loss and mortality patterns in the Glasgow Alumni Cohort. Heart (British Cardiac Society) 93, 1098-1103.

WHO \& IDF (2006) Definition and diagnosis of diabetes mellitus and intermediate hyperglycaemia. Online at http://whqlibdoc.who.int/publications/2006/9241594934_eng.pdf?ua=1.

Winning L., Patterson C. C., Neville C. E., Kee F. \& Linden G. J. (2017) Periodontitis and incident type 2 diabetes: a prospective cohort study. Journal of Clinical Periodontology 44: 266-274.

Ylöstalo P., Anttila S., Rajala U., Päivänsalo M., Keinänen-Kiukaanniemi S., Sakki T. \& Knuuttila M. (2010) Periodontal infection and subclinical atherosclerosis: the role of high-density lipoprotein as a modifying factor. Journal of Clinical Periodontology 37, 617-624.

This article is protected by copyright. All rights reserved. 
Zhang J., Gao Z., Yin J., Quon M. J. \& Ye J. (2008) S6K directly phosphorylates IRS-1 on Ser-270 to promote insulin resistance in response to TNF-(alpha) signaling through IKK2. The Journal of biological chemistry 283, 35375-35382.

Zimmet P., Alberti K. G. \& Shaw J. (2001) Global and societal implications of the diabetes epidemic. Nature 414, 782-787.

Zou G. (2004) A Modified Poisson Regression Approach to Prospective Studies with Binary Data. American Journal of Epidemiology 159, 702-706.

Figure legends:

Fig. 1. Flowchart of the formation of the study population.

Fig. 2. The number of sites with deepened ( $4 \mathrm{~mm}$ deep or deeper) periodontal pockets among subjects with periodontal pockets with probing depth of 4-5 $\mathrm{mm}$ and subjects with periodontal pockets with probing depth of $6 \mathrm{~mm}$ or more. Median, minimum, lower quartile, upper quartile and maximum in box plots.

This article is protected by copyright. All rights reserved. 
Table 1. Basic characteristics of the study population according to the categories of the presence of deepened (4 mm deep or deeper) periodontal pockets in the baseline examinations in 1990-1992

\begin{tabular}{llllr}
\multicolumn{2}{l}{ Presence of deepened periodontal pockets } & & \\
\hline No deepened & Pockets with & Pockets with & Edentulous & Total \\
pockets & probing & probing & & \\
& depth of $4-5$ & depth of 6 & \\
& $\mathrm{~mm}$ & mm or more & &
\end{tabular}

\begin{tabular}{|c|c|c|c|c|c|}
\hline Gender, n (\%) & & & & & \\
\hline Males & $37(42)$ & $39(40)$ & $52(57)$ & $28(24)$ & $156(46)$ \\
\hline Females & $51(58)$ & $59(60)$ & $39(43)$ & $90(76)$ & $239(54)$ \\
\hline $\begin{array}{l}\text { Mean number of teeth (baseline data) } \\
\left(\mathrm{SD}^{*}\right)\end{array}$ & $14.3(8.7)$ & $17.8(8.1)$ & $19.1(7.5)$ & 0 & $12.0(10.5)$ \\
\hline
\end{tabular}

Hereditary risk of diabetes mellitus

(diabetes mellitus occurrence in the

immediate family, follow-up data), n (\%)

No risk

Moderate risk

Increased risk

Missing data

Physical activity (baseline data), n (\%)

High physical activity

Low physical activity

Missing data

Dietary habits (baseline data), n (\%)

Healthy diet

Moderately healthy diet

Unhealthy diet

Missing data

Smoking status (follow-up data), n (\%)

Current smoker

Former smoker

Non-smoker

Missing data

BMI (follow-up data), n (\%)

$<25.0$

$25.0-29.9$
$5(6)$

$45(51)$

$8(9)$

34 (39)

1 (1)

69 (78)

16 (18)

3 (3)

$56(64)$

18 (21)

8 (9)

7 (7)

33 (37)

45 (51)

5 (6)

26 (30)

39 (44)
54 (55)

11 (11)

$30(31)$

3 (3)

75 (77)

$21(21)$

2 (2)

55 (56)

23 (24)

13 (13)

7 (7)

4 (4)

$41(42)$

49 (50)

4 (4)

22 (23)

$211(53)$

32 (8)

$142(36)$

$10(3)$

2 (2)

61 (67)

$98(83)$

$303(77)$

27 (30)

19 (16)

$83(21)$

3 (3)

1 (1)

9 (2)

$46(51) \quad 55(47)$

$212(54)$

$26(29) \quad 35(30)$

102 (26)

17 (19) $22(18)$

$60(15)$

2 (2)

$6(5)$

$21(5)$

52 (53)
15 (17)

$22(19)$

39 (33)

$52(57)$

$11(9)$

$30(7)$

49 (54)

$61(52)$

184 (47)

$28(31)$

$43(36)$

$165(42)$

4 (4)

3 (3)

16 (4)

182 (46)
85 (21) 
30.0 or more

Missing data

Mean change in BMI during the

follow-up period (SD*)

Absolute change in BMI during the

follow-up period, n (\%)

BMI change negative

$0 \leq$ BMI change $<2$

$2 \leq$ BMI change $<4$

BMI change $\geq 4$

Missing data

IGT (baseline data), n (\%)

Yes

No

Missing data

Hypertriglyceridemia (follow-up

data), n (\%)

Yes

No

$3(3)$

$85(97)$

9 (9)

$89(91)$

$2(2)$

$96(98)$

$4(4)$

$3(3)$

$11(3)$

No

86 (98)

Arterial hypertension (follow-up data), n (\%)

Yes

$31(35)$

$43(49)$

$14(16)$

Missing data

*Standard deviation.
$22(24) \quad 47(40) \quad 105(27)$

$2(2) \quad 10(8) \quad 23(6)$

$1.6(2.4) \quad 2.5(3.0) \quad 1.7(2.7)$
$141(36)$

$96(24)$

$61(15)$

$1(0)$

$122(31)$

$271(68)$

$2(1)$

$1(1) \quad 0 \quad 2(1)$

$78(86) \quad 99(84) \quad 351(89)$

$87(96) \quad 15(97) \quad 384(97)$

$40(41) \quad 38(42) \quad 51(43) \quad 160(41)$

$45(46) \quad 41(45) \quad 46(39) \quad 175(44)$

$13(13) \quad 12(13) \quad 21(18) \quad 60(15)$ 
Table 2. Basic characteristics of the study population according to diabetic status in the follow up-examinations in 2007-2008

\begin{tabular}{|c|c|c|c|}
\hline & \multicolumn{2}{|c|}{ Diabetic status } & \multirow[b]{2}{*}{ Total } \\
\hline & Diabetic & Non-diabetic & \\
\hline \multicolumn{4}{|l|}{ Gender, n (\%) } \\
\hline Males & $38(47)$ & $118(38)$ & $156(39)$ \\
\hline Females & $43(53)$ & $196(62)$ & $239(61)$ \\
\hline Mean number of teeth (baseline data) (SD*) & $12.5(10.5)$ & $11.9(10.5)$ & $12.0(10.5)$ \\
\hline \multicolumn{4}{|l|}{ Periodontal condition (baseline data), n (\%) } \\
\hline No deepened pockets & $13(16)$ & $75(24)$ & $88(22)$ \\
\hline Pockets with probing depth of $4-5 \mathrm{~mm}$ & $21(26)$ & $77(25)$ & $98(25)$ \\
\hline Pockets with probing depth of $6 \mathrm{~mm}$ or more & $25(31)$ & $66(21)$ & $91(23)$ \\
\hline Edentulous & $22(27)$ & $96(31)$ & $118(30)$ \\
\hline \multicolumn{4}{|c|}{$\begin{array}{l}\text { Hereditary risk of diabetes mellitus (diabetes mellitus } \\
\text { occurrence in the immediate family, follow-up data), } \\
\mathrm{n}(\%)\end{array}$} \\
\hline Low risk & $33(41)$ & $178(57)$ & $211(53)$ \\
\hline Moderate risk & $5(6)$ & $27(9)$ & $32(8)$ \\
\hline Increased risk & $42(52)$ & $100(32)$ & $142(36)$ \\
\hline Missing data & $1(1)$ & $9(3)$ & $10(3)$ \\
\hline \multicolumn{4}{|l|}{ Physical activity (baseline data), n (\%) } \\
\hline High physical activity & $64(79)$ & $239(76)$ & $303(77)$ \\
\hline Low physical activity & $15(19)$ & $68(22)$ & $83(21)$ \\
\hline Missing data & $2(3)$ & $7(2)$ & $9(2)$ \\
\hline \multicolumn{4}{|l|}{ Dietary habits (baseline data), n (\%) } \\
\hline Healthy diet & $42(52)$ & $170(54)$ & $212(54)$ \\
\hline Moderately healthy diet & $21(26)$ & $81(26)$ & $102(26)$ \\
\hline Unhealthy diet & $15(19)$ & $45(14)$ & $60(15)$ \\
\hline Missing data & $3(4)$ & $18(6)$ & $21(5)$ \\
\hline \multicolumn{4}{|l|}{ Smoking status (follow-up data), n (\%) } \\
\hline Current smoker & $4(5)$ & $26(8)$ & $130(8)$ \\
\hline Former smoker & $44(54)$ & $144(45)$ & $184(46)$ \\
\hline Non-smoker & $25(31)$ & $140(45)$ & $165(42)$ \\
\hline Missing data & $8(10)$ & $8(2)$ & $16(4)$ \\
\hline \multicolumn{4}{|l|}{ BMI (follow-up data), n (\%) } \\
\hline$<25.0$ & $12(15)$ & $73(23)$ & $85(22)$ \\
\hline $25.0-29.9$ & $37(46)$ & $145(46)$ & $182(46)$ \\
\hline
\end{tabular}


30.0 or more

Missing data

Mean change in BMI during the follow-up period (SD*)

Absolute change in BMI during

the follow-up period, n (\%)

BMI change negative

$22(27)$

$19(23)$

$24(30)$

15 (19)

BMI change $\geq 4$

Missing data

IGT (baseline data), n (\%)

Yes

No

Missing data

Hypertriglyceridemia (follow-up data), n (\%)

Yes

No

Low HDL-C level (follow-up data), n (\%)

Yes

No

Arterial hypertension (follow-up data), n (\%)

Yes

No

Missing data
$1(1)$

48 (59)

0

$18(22)$

63 (78)

$4(5)$

77 (95)

$45(56)$

$21(26)$

$15(18)$
$28(34)$

$77(25)$

$105(27)$

$4(5)$

$19(6)$

$23(6)$

$2.0(3.6)$

$1.6(2.3)$

$1.7(2.7)$
74 (24)

$96(24)$

122 (39)

$141(36)$

$72(23)$

$96(24)$

46 (14)

61 (16)

0

$1(0)$

$122(31)$

$271(68)$

$223(71)$

$2(1)$

$2(1)$

$26(8)$

$44(11)$

$288(92)$

$351(89)$

$11(3)$

$384(97)$

$307(98)$

$115(37)$

$160(41)$

$154(49)$

$175(44)$

45 (14)

$60(15)$

*Standard deviation.

This article is protected by copyright. All rights reserved. 
Table 3. Number of sites with deepened (4 mm deep or deeper) periodontal pockets according to periodontal condition

\begin{tabular}{|c|c|c|c|}
\hline & $\begin{array}{l}\text { Periodontally } \\
\text { healthy subjects } \\
(\mathrm{n}=88)\end{array}$ & $\begin{array}{l}\text { Subjects with } \\
\text { periodontal pockets } \\
\text { with probing depth of } \\
4-5 \mathrm{~mm}(\mathrm{n}=98)\end{array}$ & $\begin{array}{l}\text { Subjects with periodontal } \\
\text { pockets with probing depth } \\
\text { of } 6 \mathrm{~mm} \text { or more }(\mathrm{n}=91)\end{array}$ \\
\hline Mean number of teeth (SD*) & $14.3(8.75)$ & $17.8(8.14)$ & $19.1(7.53)$ \\
\hline \multicolumn{4}{|l|}{ Sites with probing depth of $4-5 \mathrm{~mm}$} \\
\hline Mean number of sites (SD*) & - & $3.9(3.6)$ & $11.6(8.6)$ \\
\hline \multicolumn{4}{|l|}{ Number of sites, $\mathrm{n}(\%)$} \\
\hline 0 & - & - & $2(2.2)$ \\
\hline $1-5$ & - & $75(76.5)$ & $22(24.2)$ \\
\hline $6-10$ & - & $17(17.3)$ & $23(25.2)$ \\
\hline 11 or more & - & $6(6.1)$ & $44(48.4)$ \\
\hline $\begin{array}{l}\text { Mean number of sites with probing } \\
\text { depth of } 6 \mathrm{~mm} \text { or more }\left(\mathrm{SD}^{*}\right)\end{array}$ & - & - & $3.9(5.8)$ \\
\hline
\end{tabular}

*Standard deviation.

This article is protected by copyright. All rights reserved. 
Table 4. Association of periodontal condition (the presence of periodontal pockets $4 \mathrm{~mm}$ deep or deeper or edentulousness) with the incidence of type 2 diabetes mellitus (T2DM); rate ratios (RR) with 95\% confidence intervals $(95 \% \mathrm{CI})$

T2DM in the follow-up examinations in 2007-2008

Periodontal condition Unadjusted RR (95\% CI) Adjusted* RR (95\% CI) p-value

No deepened pockets

1.00

1.00

4-5 mm deep pockets

$1.40(0.74-2.64)$

$1.32(0.69-2.53)$

NS

$6 \mathrm{~mm}$ deep or deeper pockets

$1.86(1.02-3.40)$

$1.56(0.84-2.92)$

NS

Edentulous

$1.26(0.67-2.36)$

$1.00(0.53-1.89)$

NS

Number of sites with periodontal pockets 4

$1.02(1.00-1.03)$

$1.02(1.00-1.04)$

$\mathrm{p}=0.048$ $\mathrm{mm}$ deep or deeper (continuous variable) ${ }^{\dagger}$

*Adjusted for gender, risk of diabetes mellitus, physical activity, dietary habits, smoking status, BMI, absolute change in BMI during the follow-up period (continuous variable), IGT at baseline, hypertriglyceridemia, low HDL-C and arterial hypertension. Effective $n=394$.

${ }^{\dagger}$ Adjusted for gender, risk of diabetes, physical activity, dietary habits, smoking status, BMI, absolute change in BMI during the follow-up period (continuous variable), IGT at baseline, hypertriglyceridemia, low HDL-C and arterial hypertension. Edentulous subjects excluded. Effective $n=276$.

This article is protected by copyright. All rights reserved. 
Table 5. Association of periodontal condition (the presence of periodontal pockets $4 \mathrm{~mm}$ deep or deeper or edentulousness) with the incidence of type 2 diabetes mellitus (T2DM) among participants who had never smoked; rate ratios $(\mathrm{RR})$ with $95 \%$ confidence intervals $(95 \% \mathrm{CI})$

T2DM in the follow-up examinations in 2007-2008

Periodontal condition Unadjusted RR (95\% CI) Adjusted* RR (95\% CI) p-value

No deepened pockets

1.00

1.00

4-5 mm deep pockets

$1.65(0.60-4.56)$

$1.95(0.60-6.30)$

NS

$6 \mathrm{~mm}$ deep or deeper pockets

$2.57(0.93-7.08)$

$2.34(0.72-7.61)$

NS

Edentulous

$0.63(0.16-2.47)$

$0.43(0.13-1.42)$

NS

Number of sites with periodontal pockets 4

$1.03(1.01-1.05)$

$1.03(1.00-1.07)$

NS $\mathrm{mm}$ deep or deeper (continuous variable) ${ }^{\dagger}$

*Adjusted for gender, risk of diabetes mellitus, physical activity, dietary habits, BMI, absolute change in BMI during the follow-up period (continuous variable), IGT at baseline, hypertriglyceridemia, low HDL-C and arterial hypertension. Effective $n=165$.

${ }^{\dagger}$ Adjusted for gender, risk of diabetes mellitus, physical activity, dietary habits, BMI, absolute change in BMI during the follow-up period (continuous variable), IGT at baseline, hypertriglyceridemia, low HDL-C and arterial hypertension. Edentulous subjects excluded. Effective $n=122$.

This article is protected by copyright. All rights reserved. 

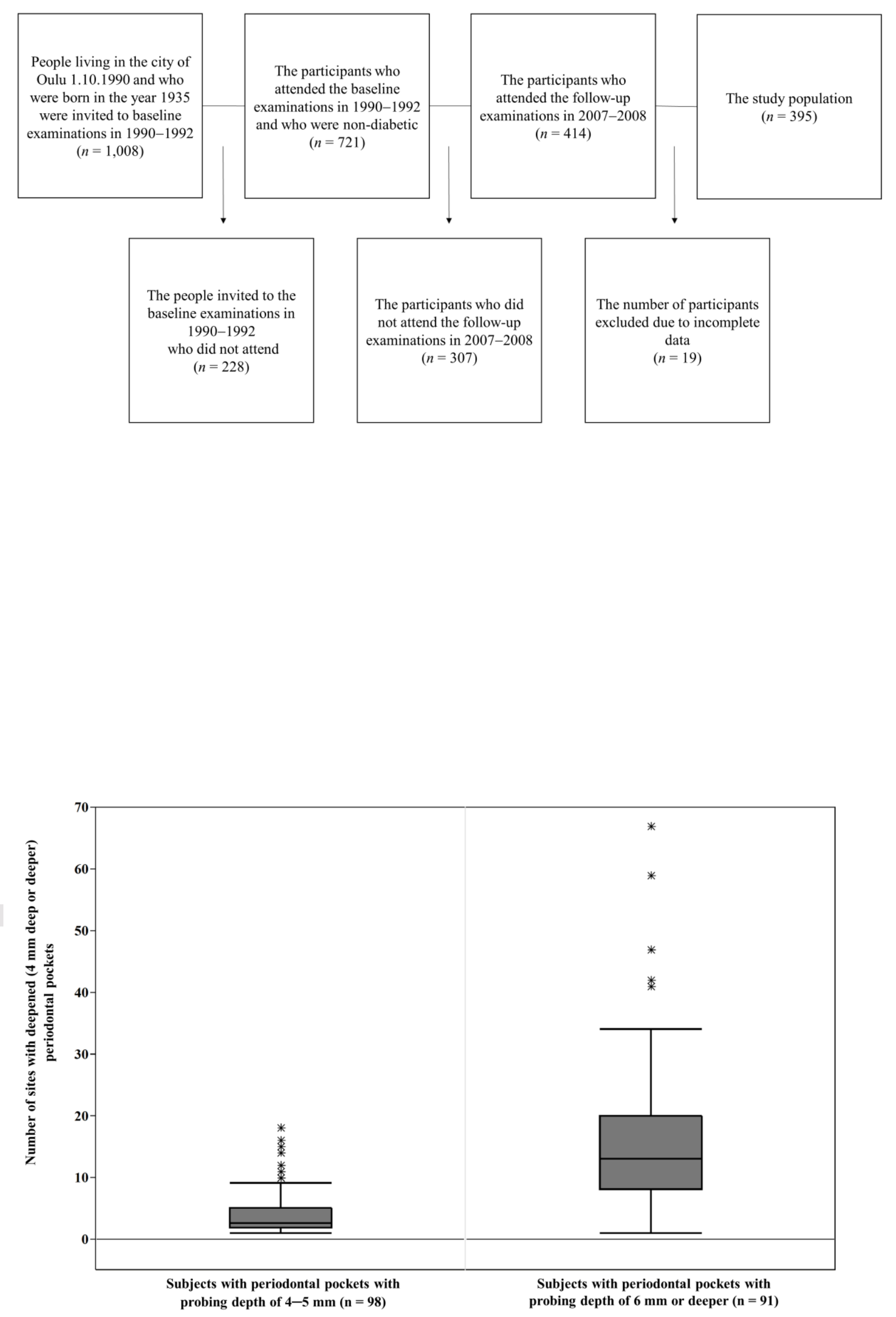

This article is protected by copyright. All rights reserved. 